\title{
A Comparison of Daedeok Innopolis Cluster with the San Diego Biotechnology Cluster
}

\author{
Sang-Tae Kim' and Gi-Don An*2 \\ SME policy Bureau, Small and Medium Business Administration(SME), ${ }^{1}$ Dept. of Economics, Chungnam National University, ${ }^{2}$ Republic of Korea
}

\begin{abstract}
This paper suggests policy implications for Daedeok Innopolis (DI) in Daejeon by comparing the development and problems of DI with the San Diego biotechnology cluster. DI has strengthened its capabilities for technology commercialization and business activities after having created and managed by the Korean central government. While DI has been successful in increasing the number of institutes, researchers, research activities, however, its dynamism is not rigorous enough to be a regional innovative system. San Diego's scientific and entrepreneurial community shows the importance of formulating social and spatial contexts for mutual interactions and engagements. In San Diego, UCSD and networking organizations, especially CONNECT, are central in promoting interactions and communications between regional constituents including entrepreneurs, academics and local governments. The mechanisms of San Diego biotechnology imply that DI should provide more attention to designing and developing social and geographical space that can unleash the creative power of social interactions. To build an innovative regional system, DI needs to renovate its space, public-private relationship and networking platforms.
\end{abstract}

Keyword:CONNECT, Daedeok Innopolis (DI), Networking, R\&D, Regional Innovation System, San Diego Biotechnology Cluster, Technology Commercialization

\section{INTRODUCTION}

Daedeok Innopolis(DI) is located in Daejeon City, sixth largest city in South Korea and transportation network hub located $170 \mathrm{~km}$ south of Seoul. Daedeok Science Town(DST) was created to enhance the national competitiveness of high technology and economic prosperity through the agglomeration of research institutes. A master plan for DST was approved in December 1973; a couple facilities and institutes were constructed in 1974. By the end of 1978, four institutes moved to the Science Town from Seoul. Due to the revision

*Correspondence to : Gi-Don An

Professor of Department of Economics, Chungnam National University, Republic of Korea E-mail : angidon@cnu.ac.kr

World Technopolis Review

Copyright $\odot$ World Technopolis Association

CC This is an open-access article distributed under the terms of the Creative Commons Attribution Non-Commercial License(http://creativecommons.org/licenses/by-nc/3.0) which permits unrestricted noncommercial use, distribution, and reproduction in any medium, provided the original work is properly cited of Daedeok Science Town Special Zone Act at the end of 2004, the Daedeok Science Town Special Zone has been renamed as Daedeok Innopolis in January 2005.

DI is the symbol and, actually, the heart of research activity in Korea. Public and private sectors in Korea have been taking a series of initiatives to facilitate the commercialization of scientific research: It has expanded the technological innovation infrastructure to form a high-tech ecosystem (Oh 2000); DI has taken steps to improve the living and investing environment for immigrant entrepreneurs. Due to efforts by governments and, partly, the private sectors, in DI, there were 1266 research and business organizations as of December 2010. Among these, about 250 research institutes are operating. The venture businesses account for over $94 \%$ of the total firms. DST accommodates top venture firms and research firms from various fields such as DRAM and SRAM semiconductor chips, LCD modules, cell phone technology, and wireless broadband technologies etc. At the moment, there are 22,000 researchers and staff carrying out research 
in cutting-edge areas and 10\% of the Korean research manpower is in DI.

Because DI is an artificial creation of the central government, DI is mainly controlled by the central government. The host city Daejeon has nothing to do with operating DI. Daejeon is only responsible for building and maintaining infrastructure such as access roads, water, sewage services, etc. This implies that DI has no local autonomy. Therefore, it is hard to improve the regional innovation system by connecting the local authority to DI. DI needs to play a role for a driving force for regional innovation. It is necessary to have a shifting development to be set in organic relationships with regional demands of technology commercialization. Furthermore, it has been widely known that developing synergistic effects of technology development is the key for sustainable growth. For developing the synergy effects, DI needs to improve the connection between research and industry through information and telecommunication technologies. DI should change activities from pure R\&D to industrial development to technology commercialization. The driving force of this change is the huge growth to venture business connected to the research institutes (Park 2004). The spontaneous entrepreneurship of venture firms is the important factors for the actual contribution of DI to the regional innovation of Daejeon Metropolitan City.

Even though DI has made the meaningful performance as a science technology park, it has not contributed to improving the regional innovative system. Especially, it has not succeeded in networking the research institutes to the local firms. Therefore, the top priority of DI is to change collaboration from passive networking to active networking building which is the critical factor for technopolis development. DI needs to develop active collaboration by various sets of networking among universities, R\&D organizations and industries.

The city of Daejeon also should make a great effort to employ DI in order to develop its economy. The city of Daejeon needs to focus on creating start-ups, nurturing a lot of small ventures by connecting them to the researchers at DI. The city of Daejeon has been very passive in employing DI for developing the economy of Daejeon. Since DI needs to contribute to the regional innovative, the city of Daejeon must collaborate with DI in order to the regional innovative system.
It is useful to analyze the San Diego Biotechnology Cluster which is drawing much attention from countries and cities around the globe. San Diego is a case that illustrates how a community of entrepreneurs, academic scientists and leaders can learn about innovation, cultivate practices of entrepreneurship and nurture a culture of collaborations. San Diego turned attention to nurturing start-ups, instead of attracting established companies from outside. With a new recognition, business, academia and public leaders reached a consensus that they could build a prosperous economy by nurturing a mass of small biotechnology and high technology companies. They turned their attention and resources to enabling and encouraging entrepreneurs and scientists to create start-ups. It was 1998 when the County of San Diego started to outperform California in terms of personal income for the first time in the modern period (refer to Fig. 1). The economic conversion occurred to a large extent the rise of the biotechnology and high technology industries.

This paper would suggest the policy implications for DI in Daejeon by analyzing how San Diego cluster has rapidly grown. It is an exploratory study suggesting the shortcomings of Daedeok and policies for reinvigorating entrepreneurship. We did researchon development and problems of DST and the biotechnology cluster of San Diego for the last 6 years. To imply the lessons from San Diego, we will trace down the historical developments of social institutions in San Diego, which involve land using planning, public-private partnership and networking organizations. The developments of these institutions have involved engagements and experiments during the last few decades, and people in San Diego have learned how to build and operate their social institutions for technology transfer and entrepreneurship.

\section{DAEDEOK SCIENCE TOWN (DST) AS A SCIENCE CITY}

\subsection{Historical Development of DST}

The government began to develop the infrastructure in order to establish a foundation for strengthening Korea's R\&D capacity in the 1970s. The plans for Daedeok Science and University Town were finalized in 1973. Construction began on Daedeok Science Town Infrastructure and Research Institutes in 1974. The government planned to expand the R\&D foundation by relocating government-funded research institutes into Daejeon. The Ministry of Science 
\& Technology's Daedeok Administration Office was installed in 1979. The National Council for Science and Technology which was established in 1973 developed into a new and more powerful institution under the chairmanship of the President of the Republic in 1982.

The government established the Daedeok Science Town Administration Center in order to strengthen creative innovation by cooperating research institutes, laying the groundwork for industry-academia research collaboration with DST in 1994. Furthermore, formation of a technology commercialization district within Daedeok Science Town was approved in 1996. As the government planned, DST boasted a large pool of qualified researchers and absorbed more than $30 \%$ of total government R\&D expenditure. Furthermore, both backward/forward linkages began to operate.

DST started to form innovation clusters by creating a scientific technological activity network and R\&D innovation cluster. The Administration of Daedeok Science Town Act was amended to perform the production functions in 1999. In order to evolve DST to the next level, the government attracted the high-tech enterprises by establishing several Acts such the Technology Transfer Promotion Law (2000), the Special Act on the Fostering of Daedeok Innopolis, etc. Finally, Daedeok Innopolis Support Headquarters was established to facilitate networking among universities, research institutes, and business firms in DI in 2005.

\subsection{Performance of DI}

There are nearly twice as many institutes $(1,266)$ in 2010 as those (742) in 2005. Among these, 30 government-funded research institutes and 1,179 private businesses are operating. As Table 1 shows, it is clear that the growth of private firms has led to increase of institutes in DI. The number of private firms has risen by almost double digits except 2009 year when the world economy experienced the global economic crisis.

Table 1. Performance of Daedeok Innopolis

\begin{tabular}{l|r|r|r|r|r|r}
\hline & 2005 & 2006 & 2007 & 2008 & 2009 & 2010 \\
\hline Total & 742 & 843 & 977 & 1,059 & 1,089 & 1,266 \\
\hline Growth Rate(\%) & & $13.6 \%$ & $15.9 \%$ & $8.4 \%$ & $2.8 \%$ & $16.3 \%$ \\
\hline public research institutes & 21 & 21 & 28 & 28 & 29 & 30 \\
\hline Growth Rate(\%) & & $0.0 \%$ & $33.3 \%$ & $0.0 \%$ & $3.6 \%$ & $3.4 \%$ \\
\hline private firms & 687 & 786 & 898 & 980 & 1,006 & 1,179 \\
\hline Growth Rate(\%) & & $14.4 \%$ & $14.2 \%$ & $9.1 \%$ & $2.7 \%$ & $17.2 \%$ \\
\hline others & 34 & 36 & 51 & 51 & & 54 \\
\hline Growth Rate(\%) & & $5.9 \%$ & $41.7 \%$ & $0.0 \%$ & $5.9 \%$ & $5.6 \%$ \\
\hline
\end{tabular}

Source: Daedeok Innopolis (2010).
In 2010, the total employment was 55,614 of which 24,434 are researchers and engineers and 31,180 are working on R\&D supporting organizations in DI. The number of researchers has increased by 13\%, and 19\% in 2009 and 2010 respectively.

Table 2. Employment of Daedeok Innopolis

\begin{tabular}{c|r|r|r|r|r|r}
\hline \multirow{2}{*}{ Year } & \multicolumn{4}{|c|}{ Researchers(A) } & $\begin{array}{c}\text { R\&D supporting } \\
\text { Employees }\end{array}$ & $\begin{array}{c}\text { Total } \\
\text { Employment }\end{array}$ \\
\cline { 2 - 7 } & Doctors & Masters & Others & Total & (B) & $(\mathrm{A}+\mathrm{B})$ \\
\hline 2010 & 9,055 & 9,736 & 5,643 & 24,434 & 31,180 & 55,614 \\
\hline 2009 & 7,661 & 8,191 & 4,670 & 20,522 & 25,004 & 45,526 \\
\hline 2008 & 6,783 & 7,253 & 4,173 & 18,209 & 23,429 & 41,638 \\
\hline 2007 & 6,800 & 7,669 & 4,327 & 18,796 & 21,542 & 40,338 \\
\hline 2006 & 6,495 & 9,145 & 2,892 & 18,532 & 18,692 & 37,224 \\
\hline 2005 & 6,236 & 7,561 & 2,962 & 16,759 & 6,799 & 23,558 \\
\hline
\end{tabular}

Source: Daedeok Innopolis (2010).

DI has improved the capability of its R\&D activities since 2005 when DI was redesigned as DI. As a result, DI has experienced the rapid increase in high numbers of domestic and international patents as well as technology transfers. The patent has been one of major driving forces in DI by strengthening DI's competitiveness as well as bridging commercialization. The number of applied patents increased 488\% from 1997 to 2002 and that of enrolled patents rose $388 \%$ during the same period. The reason is that the number of venture firms dramatically rose in DI because the government changed the law in 1999 in order to bring venture businesses within DI. Even though venture businesses started in 1993 around DI, these businesses were not able to be located within the park due to the Law for Daedeok Science Town Management (Park 2004). Because this law was widely known as resulting in weak spin off effects between R\&D and manufacturing, the government changed this law in 1999 in order to bring venture businesses into the park.

Table 3. Research outputs of Daedeok Innopolis

\begin{tabular}{r|r|r|r|r|r|r}
\hline \multirow{2}{*}{ Year } & \multicolumn{5}{|c}{ Patents } \\
\cline { 2 - 7 } & \multicolumn{3}{|c}{ Applied } & \multicolumn{3}{c}{ Enrolled } \\
\cline { 2 - 7 } & Domestic & International & Total & Domestic & International & Total \\
\hline 2010 & 10,525 & 3,854 & 14,379 & 4,953 & 1,535 & 6,488 \\
\hline 2009 & 8,818 & 3,917 & 12,735 & 3,800 & 1,359 & 5,159 \\
\hline 2008 & 8,480 & 3,894 & 12,374 & 4,883 & 1,098 & 5,981 \\
\hline 2007 & 7,065 & 3,246 & 10,311 & 5,377 & 833 & 6,210 \\
\hline 2002 & 7,447 & 1,760 & 9,207 & 3,630 & 698 & 4,328 \\
\hline 1997 & 1,376 & 262 & 1,638 & 746 & 141 & 887 \\
\hline 1996 & 1,082 & 259 & 1,341 & 326 & 129 & 455 \\
\hline 1995 & 1,115 & 317 & 1,432 & 297 & & 297 \\
\hline
\end{tabular}

Source: Daedeok Innopolis (2010). 
The technology transfers have continually increased since 2005 , except when the global economics crisis happened in 2009. The transfer fees have rapidly increased by $111 \%$ from 2005 to 2010. Especially, the technology transfers to venture business were $80 \%$ of total technology transfers in DI. The increase in the number of venture businesses and technology transfers has been the key factor of growth in DI. The number of venture business which has a venture certificate increased up to 589 in 2010. In addition to new venture businesses, enlarging industrial contributed to the rapid increase in DI. Daejeon metropolitan government has built two hightech based industrial parks near to DI in order to generate spin-off effects from the research results of DI (Daedeok Science Town Management Office 2002b). As a result, the number of ventures registered in the Korea Stock Exchange (KSE) has increased from 11 in 2005 to 24 in 2010. DI is able to improve an innovative cluster by connecting activities like technology transfers from R\&D to production activities.

Table 4. Technology Transfers and Fees

\begin{tabular}{c|c|c}
\hline Year & Transfers & Fees \\
\hline 2010 & 778 & 110,319 \\
\hline 2009 & 910 & 109,394 \\
\hline 2008 & 974 & 95,723 \\
\hline 2007 & 815 & 77,798 \\
\hline 2006 & 723 & 61,205 \\
\hline 2005 & 611 & 52,408 \\
\hline
\end{tabular}

Source: Daedeok Innopolis (2010).

\subsection{Problem of DI}

Since DI is mainly controlled by the central government, the host city Daejeon doesn't have any authority to be involved in operation of DI. The government of Daejeon has nothing to do with creating programs to connect the R\&D results to the local businesses in the Daejeon region. Therefore, DI has not contributed to enhance the regional innovative system in the Daejeon region by connecting the research institutes to local firms. The regional innovative system can be developed as long as the R\&D results are commercialized by the innovative venture business. However, DI has worked as a national innovative system because it is financed by the central government.

However, the Special Act on the Fostering of Daedeok Innopolis was amended in order to emphasize the role of Innopolis in contributing to the regional innovative system. As a result of this Act, two Innopolis Support Headquarters were established in January 2011: Daegu Innopolis and
Gwangju Innopolis Support Headquarters. DI begins to focus on not only the regional innovative system but also the national innovative system. In order for DI to improve the regional innovative system, it develops programs of connecting researchers with local firms in DI. DI would be well served to benchmark CONNECT in the San Diego biocluster as a successful networking program among the local research institutes, universities, and venture firms.

Because DI is a government-led establishment, most of the research institutes and its agencies usually have a strong tendency to focus on huge national R\&D activities rather than the interests of small local venture company. Therefore, there are few connections between the research activities in DI and production activities in Daejeon. This kind of weak connection between research and manufacturing activities has resulted in poor local synergy. However, the central government realized that developing local synergy effects is the key factor for maximizing the effects of technology development. DI has focused on synergy effects in a comprehensive plan by authorizing DI as R\&D Special Zone in 2005. DI has undergone a restructuring process by stimulating new high-tech oriented venture businesses within and around DI. In order to generate synergy effects, DI has to intensify cooperative relationships between government supported industries, universities and industrial laboratories.

\section{IMPLICATIONS FROM SAN DIEGO FOR REINVIGORATING DAEDEOK, KOREA}

The most critical divergence between San Diego and DI is the easiness of interacting and communicating. In other words, the social and spatial contexts of the two cities have developed in different paths, and the differences have resulted in divergent levels of entrepreneurship. In contrast to San Diego, Daedeok has failed to develop the social and geographical spaces where scientists could easily mingle with entrepreneurs and embark on commercial endeavors. The boundaries in Daedeok between the scientists and entrepreneurs communities exist in threefold: the geographical separation between research institutes and commercialization facilities; the dearth of social organizations which connect individuals and groups with each other; the lack of partnership between the public and private sectors. 


\subsection{Reconstitute Land Use Planning for Entrepreneurship}

Among the contexts in San Diego, high-tech and biotechnology enterprises are located in the same research and academic institutes. Zoning does not prohibit the industrial developments in the Scientific Research area. To foster growth, parcels of land were left for commercial developments next to research institutions in San Diego. Legally, the land use zoning of DI does not prohibit the development of industrial facilities around research institutes as indicated in Fig. 1. However, from the beginning of the town, the science park was envisioned and developed as a heavenly collection of scientific endeavors. Each research institute was allotted its land enclosed by gates and fences. During the early years of DI, the initiators were not serious in nurturing commercialization activity leveraging research capacity of the town. Research institutes usually have their own playgrounds, dormitories and other facilities on their site, so they can thrive in isolation. Furthermore, parcels for land development are separated by natural barriers like hills and rivers in Daedeok. Each research institute, so to speak, has built its own kingdom.
As illustrated in Fig. 1, the San Diego cluster is almost seamlessly linked by its landscape, research institutes and biotechnology companies share the entire land together rather than building their own fences. To overcome the shortcomings of this zoning regulation, research institutes in DI have installed business incubators for, mostly, spinouts, but this response has not narrowed the gap between industries and research institutes to a significant level.

The spatial arrangements of San Diego's community are the result of a historical endeavors and engagements by both the public and private communities. A large number of biotechnology and high-technology companies are around UCSD and research institutes as shown in Fig. 1. The most critical event that has led the coexistence of industries with academia is the designation of the Life Sciences-Research zone just north of UCSD. The basic idea of the Life Sciences-Research zone of San Diego was to create a campus like environment, which would be attractive to talent and enterprises.

In the 1983 plan, the city designated parcels of land as the Scientific and Research Zone, which is similar to Fig. 3 of

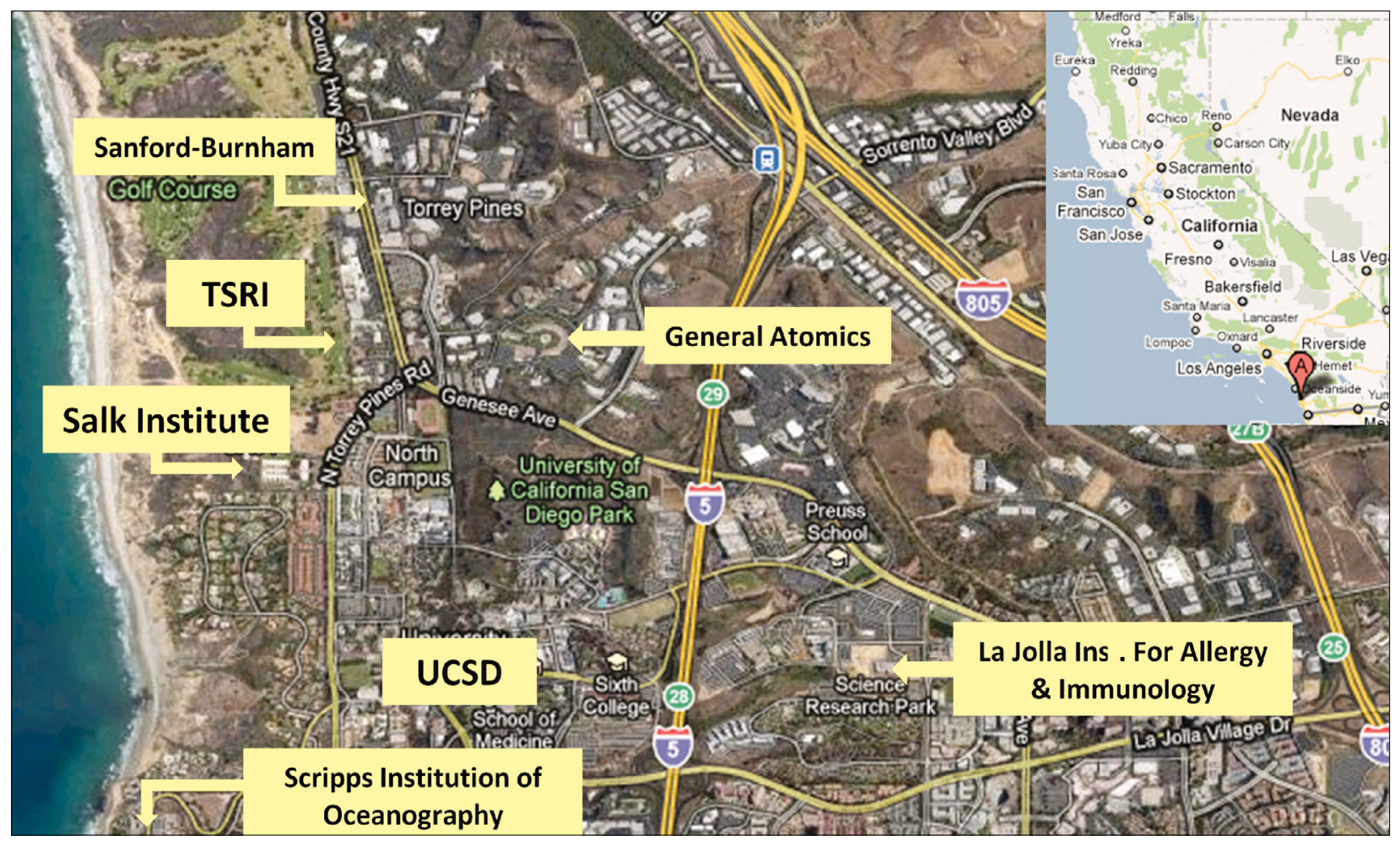

Fig. 1. Aerial view of research institutions on Torrey Pines Mesa

- Adopted from Kim (2011).

- Note: General Atomics is not a research institute but a firm. However, it contributed to creating a large number of research institutes by producing research-based commodities. 


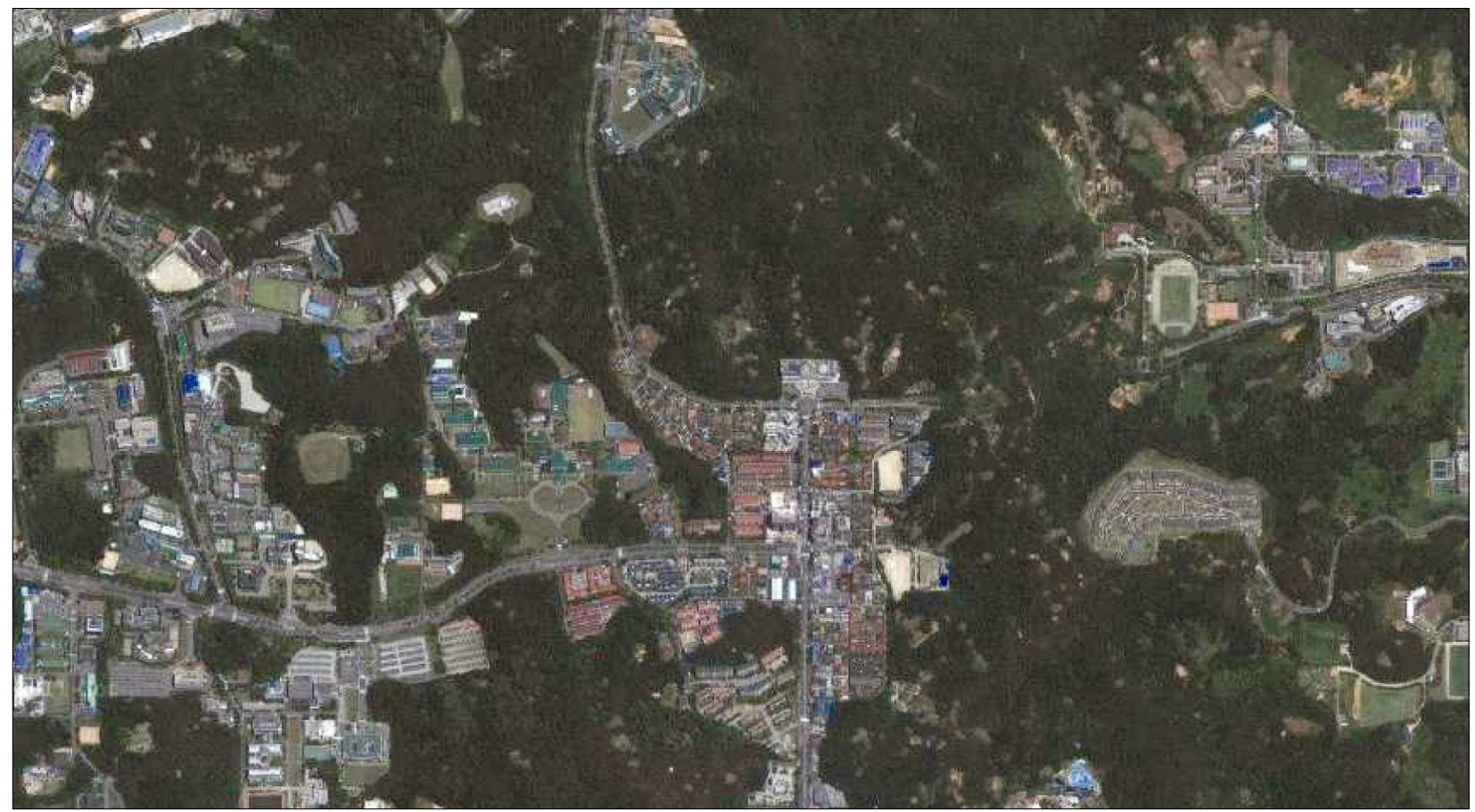

Fig. 2. Aerial view of DI in Daejeon

Source: Aerial photo by the Google Maps on http://maps.google.com

1987 plan. Most non-profit research institutions, including the Salk Institute, TSRI, the Sanford-Burnham Institute, pharmaceutical companies' research facilities and large number of biotechnology companies are located within this zone. The 1983 plan specified the permissible facilities in the zone: "The uses contemplated within the ScientificResearch (SR) Zone are research laboratories, supporting facilities, headquarters or administrative offices and personnel accommodations, and related manufacturing activities" (City of San Diego 1983).

Each development project in the Scientific and Research Zone must go through a review process whereby the city examines the quality and cohesiveness of the proposal. Through this process, the city has implemented the principles and standards of the plans not just for land uses, but also densities, heights, building designs, building materials and landscaping. A city official (Gibbon, interview) described the regulatory process and the principles:

\section{"... Whether the city developed itself or sold to private} developers who would have completed the development process, they created fairly strict development and design standards for each industrial park. As opposed to

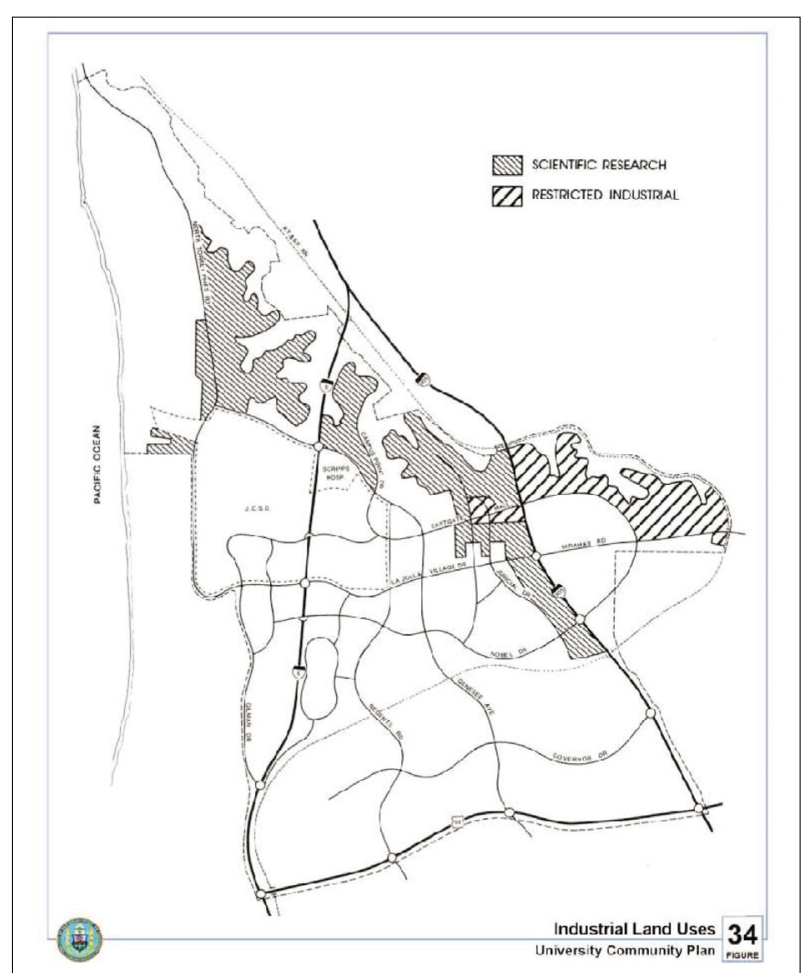

Fig. 3. Scientific and Research Zone in the 1987 plan Source: City of San Diego(1987) p. 212. 
traditional industrial parks which might be a large flat area of concrete and streets without trees or plants, they wanted to create very high-end industrial parks where people feel almost like a college campus...."

He explained that the cluster would not have been possible without the city's land use planning. La Jolla, he said, would be like 'Century City or Santa Monica' which is filled with commercial buildings like office buildings, shopping centers and high-end houses. According to him, the main concept and intention of the planning was to "develop in a way that takes advantage of the university" even though it would take a long time to realize the vision (interview). And "by preserving and setting this idea" for at least two decades, the city began to reap the fruit beginning in the 1980s, as Gibbon (interview) explained:

“...It's not an accident. It's because we knew we had this, we got this land. We don't want anything else here. It's got to be biotech and scientific research because this is focused on chemistry and biology...."

Joseph Panetta, CEO of BIOCOM, also attributed the daily interactions to the geographical proximity between institutions and companies:

“...UCSD, Salk, Scripps, Burnham, Venter Institute, La Jolla Institute, all of these are right in the middle of the biotech industry, surrounded by all the companies. Literally, across the street are all these companies... The reason that we've got this environment where scientists and industry interact so closely is just because we are right there next to each other. All the time, we see each other. ..." (interview)

As they live and work next to each other, there is a constant flow of interactions back and forth. Peter Kuhn (interview), a professor of TSRI, also attributed the robustness of interactions to spatial closeness. Every academic scientist can reach to any partners at neighboring research institutions or related companies within ten minutes either by walking or driving: "everybody is physically so close." In San Diego, as Gary Firestein, a professor of UCSD, explains (interview), academic scientists are "surrounded by hundreds of biotechnology companies."
In this respect, the City of Daejeon needs to allow and, in some ways, promote securing commercial facilities next to research institutes. Research institutes can utilize their underutilized land in building commercial spaces and they need to open up their facilities, so anyone can easily access to them. By locating entrepreneurs just outside their laboratories and inviting them to their laboratories, they can create synergy effect for exploratory and commercial endeavors. To achieve this goal, the city, public agencies and research institute should begin discussions to find the best practices.

\subsection{Public-private Partnership for Collaboration}

In the process of developing DI, the private sector has been marginalized. It was the Korean central government, which instituted and executed the development plan. Even though, the City of Daejeon has become more involved in managing the DI, still, the central government owns most resources and distributes them at its discretion. The private sector has not participated in the decision making process to a significant extent. Entrepreneurs and scientists organized associations like Daedeok 21, but these organizations are more for social interactions, not much for involvement in public policies.

In San Diego, the private sector has been an important partner with the public sector in making critical decisions. To be more, the partnership was developed through interactions between the two sectors during the last few decades.

From the beginning, biotechnology start-ups came across adversities which required collective actions. As the region lacked a significant tradition and experience of life sciences industries, the communities of entrepreneurs had to build large a part of the infrastructure and institutions on their own: they had to explore and enact ways of working with local governments; they had to devise plans and put them into action to overcome difficulties, for example, in attracting venture capital and employing talent.

The first significant confrontation with the public sector was the city's zoning regulations in La Jolla. After several years of R\&D activity, many biotechnology companies needed manufacturing facilities and expanded research laboratories by the early 1990s. In pursuing permits, they encountered conflict with the local government. A developer, James McGraw, noted the concerns of the biotechnology companies:

For example, there's a lack of predictable timing in the planning and development process. There are a number of 
hoops you have to jump through ranging from community group review of the proposed facility to last-minute environmental concerns. Time is critical for these guys because they have commitments to their investors to come on line. (Quoted in Fikes 1991a)

Similarly, an early biotechnology entrepreneur, David Hale, commented: "Much of the frustration is the perceived attitude of the City Council and city government in terms of support of this industry. I think attitude is a key issue." (Fikes 1991b)

And worse, in 1991 the city introduced a water-rationing program, which would discontinue the water supply for a few hours every day to industries. Moreover, a group of local environmentalists proposed an ordinance, the 'Toxic Free Neighborhoods Ordinance' in the same year. According to the ordinance, industries were obliged to report any hazardous materials, which most biotechnology companies had to use (Fikes 1991c). The biotechnology industry had the most concern over the conflicts and confrontations with their local governments. A biotechnology entrepreneur, Jerry Caulder, complained: "Just penetrating the bureaucracy is difficult (in San Diego), and it's hard to predict what the (requirements) are going to be for everything from water to manufacturing" (Douglass 1992).

In 1991, a group of biotechnology entrepreneurs formed the association BIOCOM, originally named the Biomedical Industry Council, to confront the city's water-rationing program. As much as the biotechnology community lacked the understanding of the political process of the city government, the city also did not understand the needs of this new industry. The early 1990s was a period when dozens of biotechnology companies completed the process of discovery and early clinical trials, so they wanted to install manufacturing facilities beside their R\&D facilities on the Torrey Pines Mesa (Fikes 1992). As a consequence, a series of conflicts and confrontations arose around issues like environmental ordinances (the Toxic Free Neighborhoods Ordinance), construction of manufacturing facilities in the Scientific and Research Zone and the regulatory process for building permits.

To tackle the demands and threats of the biotechnology industry, the city government introduced several mechanisms to communicate with the industry. First of all, the City of San Diego convened a taskforce team, the San Diego Economic Development Task Force, consisting of a group of business people to identify issues and suggest recommendations
(Fikes 1991c). In 1992, the city designated one of their public officials as a biotechnology ombudsman who would bridge between the public and private sectors (Douglass 1992). In the same year, the City Council of San Diego held a session, the Biotech Summit, to discuss issues with two associations of biotechnology industry: the Biomedical Industry Council and the BioCommerce Association, which merged to be a single association, BIOCOM (Rose 1992). As products of these interactions, the city government adopted a set of programs and processes to reflect the demands of biotechnology industry into policies: in 1992, the city took actions to shorten the regulatory review for construction permits and allowed biotechnology companies to build manufacturing facilities in the Scientific and Research Zone under certain conditions (Brydolf 1992; Fikes 1992); in 1993, the city led an effort to open a one-stop center, the San Diego Regional Permit Assistance Center, where 14 regulatory agencies convened in one space, to trim down the time for acquiring building permits.

The conflicts between the local government and the biotechnology industry turned into a convergence of interests and initiatives as the result of interactions and involvement. The conflict around the water-rationing plan, for example, was resolved when both sides came to an arrangement in which the biotechnology companies voluntarily would participate in water reclamation and conservation programs and the city would exempt them from mandatory conservation measures.

The city needed to understand, as a manager of San Diego City (interview) described, "the very specific needs of the biotechnology industry from the policy perspective" and undertake actions to address the needs of the industry. Thus, "a lot of things are about understanding and addressing their concerns from the policy perspective by making sure the city has plans, ordinances and codes."

To the biotechnology community, a core part of its partnership with local governments has been to understand the public sector and build relationships with it. Lynne Parshall, senior vice president of ISIS Pharmaceuticals, in the City of Carlsbad - which is about 20 miles north of La Jolla and is the second largest hub of biotechnology companies in the County of San Diego - explains how the two sides came closer: "We've become more sophisticated. We know and understand the rules, the players, better. We've gotten to know the people in city government more, and know who is the right person to call for this thing or that thing" 
(Fikes 1995). As a consequence of interactions and involvement from the 1990s, public and private sides both learned how to collaborate. As Joseph Panetta, CEO of BIOCOM, explained:

"...We have also very close relationships with local governments. Sometimes, small companies need to get some approval from the city to build building, to build specialized laboratories or facilities. We work directly with the city and local governments to help these companies get approval. ..." (interview)

As implied in the process, entrepreneurs of DI need to develop their own arrangements to participate in public policies. Through these arrangements, entrepreneurs can develop policy agendas reflecting their needs, and negotiate with the public sector. More importantly, the public sector needs to recognize the importance of public-private partnership because the process of participating in policy making gives the incentives and initiatives for entrepreneurs to collaborate. By building the platform for participating in policy making, and actually negotiating with the public sector, entrepreneurs can learn how to collaborate with each other.

\subsection{Social Spaces for Interactions and Learning}

Different from DI, entrepreneurs and scientists in biotechnology and high-technology sectors in San Diego have developed a number of networking organizations. The emergence and growth of networking organizations has been largely organic, by which we mean they were organized by the private sector. A large part of activities and programs for stimulating entrepreneurship in San Diego is carried out by these associations including CONNECT, BIOCOM, CleanTECH San Diego, and CommNexus San Diego.

In contrast in DI, no significant organization emerged as a node of networking or interacting. Entrepreneurs in DI organized an association named 'Daedeok 21 Century' in 1996, which was renamed as Daedeok Innopolis Venture Association. The City of Daejeon and the Innopolis Foundation support the formation of networking organization by granting operating costs, but failed, until now, to fuel synergy effects by such organizations.

Like the formation of zoning regulations and public-private partnership, the development of networking organizations in San Diego was the consequence of efforts by the community for the last few decades.
Among a group of such organization, CONNECT is the oldest and leading one, which is recognized as one of the most successful platforms for entrepreneurship. CONNECT was conceived and constructed as a consequence of engagements and experience during the failed efforts to locate research consortiums. Richard Atkinson, chancellor of UCSD, was involved in the series of failed efforts to attract research consortiums in 1984, 1985 and 1987. Especially, during a series of discussions to locate MCC, the participants recognized that the university and industry were separated from each other. Daniel Pegg (interview) said of the recognition:

"... Out of that competition for MCC, came recognition that we really didn't have the connection to our university resources. We needed to bridge between the private sector and the university. The concept was to help bring the university leadership, internal talent and the scientific resource together with their counterparts in the private sector..."

The group of individuals including Atkinson and hightech entrepreneurs held a series of discussions to find ways to facilitate the interactions between UCSD and industries. Pegg (interview) recounted the process of initiating a new program:

"...We got together, and discussed different possibilities and different ways to approach the issue and to finance. It just grew from there. Then, shortly after, we had an initial concept, and it was, in great part, the work of Mary Walshok and those who originally sat around the table and discussed the issue...."

This program was originally named 'Program in Technology and Entrepreneurship', as part of the university's Extended Studies and Public Programs, and later it was renamed CONNECT. The early focus was to integrate the competency of UCSD and local industry by stimulating interactions and interchanges. To the people from industries, UCSD was too bureaucratic and detached from the local economic life. To achieve the goal, the both sides needed an intermediary agent which would bridge the chasm. Walshok (Eger and Walshok 2008) stated the vision of the program: 


\begin{abstract}
"...The whole premise of this CONNECT program was that you can turn promising inventions and ideas into viable businesses for which there are markets, where you can make money and create jobs if you can link the research university with the business community and the financial community, and build teams that can take an idea into the commercial market place...."
\end{abstract}

In 1991, a group of CEOs of biotechnology companies and service providers formed a trade association, BIOCOM. Another trade association of software companies, the San Diego Software Industry Council, was set up in 1992. In the following years, a group of trade associations and a series of communal initiatives emerged in San Diego to deal with each group's specific issues.

Like CONNECT and BIOCOM, organizations including the San Diego Tech Coast Angels, the CleanTECH San Diego and the San Diego Venture Group have been another channel for engagements, interactions and participations. Along with the learning experience at companies, these organizations and their programs have helped create a social space for convening and conversing, which have promoted cross-fertilization of knowledge and practices between communities of entrepreneurs. In this respect, constituents of DI should give more emphasis on forming active associations, whereby they interact to solve problems and to initiate programs for entrepreneurship.

\section{CONCLUSIONS: POLICY SUGGESTIONS FOR DI}

This paper suggests the policy implications for DI in Daejeon by comparing the development and problems of DI with the rapidly growing San Diego cluster. DI has contributed to strengthening the capabilities for technology commercialization and business activities after DI was artificially created by the central government. It is widely known that DI has played a key role in the dramatic growth of the Korean economy through technology development. It has expanded innovation clusters by creating a scientific technological activity network and R\&D innovation cluster.

DI has rapidly grown by being restructured several times. The number of institutes has grown from 742 in 2005 to 1,266 in 2010. Especially, the growth of private firms has led to increase of institutes in DI. There are 24,434 researchers who are working in DI. The number of researchers also grew by $19 \%$ in 2010 . DI has improved its capability of R\&D activities. DI has also experienced the rapid increase in the research activities such as high numbers of domestic and international patents. The technology transfers have continually increased by strengthening DI's competitiveness as well as bridging commercialization. Especially, venture business plays a great role in the technology transfers, in which the technology transfers to venture business were $80 \%$ of total technology transfers in DI. The number of ventures registered in the Korea Stock Exchange (KOSDAX) has increased from 11 in 2005 to 24 in 2010.

However, DI has a few of problems to enhance the regional innovative system. First, because DI is financed by the central government, it does not have any responsibility for being involved in the regional innovative activities. DI has not contributed to improve the regional innovative system in the Daejeon region by connecting the research institutes to the local firms. However, the role of DI has changed by focusing on the regional innovative system more than the national innovative system. In order for DI to improve the regional innovative system, it develops the programs of connecting the researchers with the local firms in DI.

The experience of San Diego's scientific and entrepreneurial community shows the importance of formulating social and spatial contexts for mutual interactions and engagements. The community which enables individuals to solve problems and to learn skills through interacting and collaborating with colleagues thrives as a habitat of entrepreneurism. Regions like Silicon Valley, Kyoto in Japan and Third Italy all represent the importance of spaces and institutions for collaborations. San Diego, which arose as a relatively new hot spot for biotechnology entrepreneurship, has been successful in creating multiple communities, in which participants create and share their knowledge and practices through interactions and engagements in the problem-solving process.

In San Diego, UCSD and trade associations promoted interaction and communication between people: many entrepreneurs and scientists came out of the university and kept up interactions with colleagues by attending lectures and events at UCSD and CONNECT. The University Community Plan and its Scientific and Research Zone also played a pivotal role in generating the cluster by facilitating face-to-face interactions. Local governments might pay more attention to designing and developing a space that can 
unleash the creative power of social interactions. The focus must be given to develop institutions and conditions for collaborative interactions. As suggested in the previous section, DI needs to renovate its space, public-private relationship and networking platforms.

\section{REFERENCES}

City of San Diego. (1983). University community plan (San Diego, CA: Planning Department of the City of San Diego).

City of San Diego. (1987). University community plan (San Diego, CA: Planning Department of the City of San Diego).

Daedeok Innopolis. (2010) Internal Statistical Materials (Daejeon, Daedeok Innopolis).

Daedeok Innopolis (2010) Comprehensive Plan and Mid and Long Term Development Strategy (Daejeon Daedeok Innopolis).

Douglass, E. (1992) “San Diego's biotech train builds up momentum and out-of-state recruiters want it to roll their way," San Diego Union-Tribune February 9, 1992.

Eger, J., and Walshok, M. (2008) "Vital role of the "third sector" in fostering an innovative economy," Envision San Diego: the Innovation Economy, SignonSan Diego, podcast audio, January 22, 2008, http://signonradio. com/programs/envision-san-diego-innovationeconomy.

Fikes, B. (1991a) "Can biotechnology continue to do business here?" San Diego Business Journal (July 1, 1991).

Fikes, B. (1991b) "Biotech leaders form industry lobby group," San Diego Business Journal (August 19, 1991).

Fikes, B. (1991c) "Biotechs fear toxics proposal," San Diego Business Journal (August 19, 1991).

Fikes, B. (1992) "City to biotechs: Stay put, we'll ease manufacturing setup," San Diego Business Journal. (August 24, 1992).

Fikes, B. (1995) "ISIS and Carlsbad forging biotech partnership," San Diego Business Journal (May 22, 1995).

Kim, H. Y. (2009) "The Making of a Science Town: The Case of Daedeok, Korea," Journal of the Economic Geographical Society of Korea 12(1): 83-95.

Kim, S-T. (2011) “An Emergence of a Biotechnology Cluster: Knowledge, Practice and Culture of the
San Diego Biotechnology Community.” PhD diss., University of California, Irvine, 2011.

Park, S-C. (2004) "The City of brain in South Korea: Daedeok Science Town," Journal of Technology Management 28: 602-14.

Oh, D. S. (2000) "Technopolis and the promotion of hightech venture businesses: The case of Taedok Research Complex," Journal of the Korean Regional Development Association 12(3): 44-61.

Rose, C. (1992) "Biotech leaders, council hold 'summit': Industry gives suggestions for expansion," San Diego Union-Tribune (March 20, 1992).

\section{Website}

www.innopolis.or.kr

http://maps.google.com 